\title{
Educación para el cambio en una sociedad hiperconectada: Cuando el otro ser se virtualiza
}

\author{
Education for Change in a Hyperconnected Society: When the Other is Virtualized
}

\section{Educação para a mudança numa sociedade hiper conectada: quando o outro se torna virtualizado}

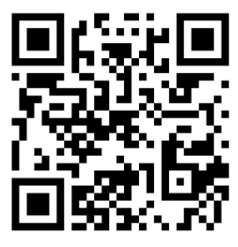

Resumen:

Introducción. La sociedad de la hiperinformación no conlleva ni supone el hiperconocimiento, ni siquiera el simple conocimiento. La sensación de asfixia ante el bombardeo continuo de lo otro, que no necesariamente del otro ser o de los otros seres, hace que la persona sintiente perciba que el pensar es un sobreesfuerzo de discriminar lo útil de lo innecesario. Objetivo. Con el presente ensayo pretendemos reflexionar acerca de los elementos socio-personales de nuestra cultura actual que interrogan el quehacer educativo exigiéndole asumir nuevas respuestas; pero, sobre todo, una vuelta a los orígenes dialógicos, puesto que, más que nunca, sentimos que nos rodean sin identificar, muchas veces, quién o quiénes. Discusión. La información aparece de forma ilusoriamente gratuita, sin aparente intencionalidad, sin metas, sin un propósito dialógico. El cara a cara se difumina en imágenes virtuales sin textura natural, pero representando algo que sacia y conforma a la persona consumidora de hoy. Lo ilusorio toma cuerpo e interactúa como quien sostiene una caña de pescar con su presa al otro extremo: esperando pacientemente; utilizando magistralmente el arte del engaño -conocimiento-; sabiendo cuándo y no necesariamente a quiénes con un sentido narrativo. Ante esto, la importancia del pensamiento crítico y del pensamiento consciente resultan estrategias fundamentales para defender un principio de realidad ontológico. Conclusiones. La educación juega un papel decisivo en el entramado de lo virtual, porque seguimos hablando de personas físicas y, más aún, de la educación con un propósito claro de cambio para la vida plena.

Palabras claves: Comunicación interpersonal; psicología de la educación; filosofía de la educación; alteridad; aprendizaje virtual. 
http://doi.org/10.15359/ree.25-3.39

http://www.una.ac.cr/educare

educare@una.ac.cr

\begin{abstract}
:
Introduction. The hyper-information society does not involve or imply hyper-knowledge, not even simple knowledge. The sensation of asphyxiation before the continuous bombardment of the otherness, which is not necessarily of the other or the others, makes the sentient person perceive that thinking demands an extra effort to discriminate the useful from the unnecessary. Objective. With this essay, we intend to reflect on the socio-personal elements of our current culture that question the educational task, demanding new answers but, above all, a return to the dialogical origins, since, more than ever, we feel surrounded without identifying, many times, who is or are surrounding us. Discussion. The information appears in an apparently free form, without apparent intentionality, without goals, and without a dialogical purpose. The face-to-face is blurred in virtual images without natural texture, representing something that satisfies and conforms to today's consumer. The illusory takes shape and interacts like someone holding a fishing rod with its prey at the other end: waiting patiently, masterfully using the art of deception -knowledge--, knowing when to wait and not necessarily whom to wait for with a narrative sense. In the face of this, the importance of critical and conscious thinking are fundamental strategies to defend a principle of ontological reality. Conclusions. Education plays a decisive role in the network of the virtual because we are still talking about physical people and, especially, about education with a clear purpose of change for an entire life.
\end{abstract}

Keywords: Interpersonal communication; educational psychology; educational philosophy alterity; virtual learning.

\title{
Resumo:
}

Introdução: A sociedade hiper informadora não envolve ou implica um hiper conhecimento, nem mesmo um simples conhecimento. A sensação de asfixia frente ao bombardeio contínuo do outro, que não necessariamente do outro ou dos outros seres, faz a pessoa que sente perceba que o pensar é um sobre esforço para discriminar o útil do desnecessário. Objetivo. Com este ensaio pretendemos refletir sobre os elementos socio-pessoais da nossa cultura atual que questionam a tarefa educativa, exigindo novas respostas mas, sobretudo, um regresso às origens dialógicas, uma vez que, mais do que nunca, nos sentimos cercados sem identificar muitas vezes por quem. Discussão. A informação aparece de uma forma aparentemente livre, sem intencionalidade aparente, sem metas, sem um propósito dialógico. O face a face é desfocado em imagens virtuais sem textura natural, representando algo mas que satisfaz e conforma o consumidor de hoje. O ilusório toma forma e interage como uma vara de pesca com sua isca: esperando pacientemente; usando magistralmente a arte do engano -o conhecimento-, sabendo quando e não necessariamente quem com um sentido narrativo. Diante disso, a importância do pensamento crítico e consciente são estratégias fundamentais para defender um princípio de realidade ontológica. Conclusões. A educação desempenha um papel decisivo na rede do virtual porque ainda estamos falando de pessoas físicas, e mais ainda, educação com um claro propósito de mudança para uma vida plena.

Palavras-chave: Comunicação interpessoal; psicologia educacional; filosofia educacional; alteridade; aprendizagem virtual. 


\section{Introducción}

Partimos del presupuesto de que la educación es un bien necesario, aunque no suficiente, para favorecer el cambio en la persona y en la sociedad. El tipo de cambio irá influenciado por un cúmulo de variables que interactúan entre sí y que tienen mayor o menor peso específico en el proceso de construcción personal del individuo. Hoy en día, el papel específico que el medio y las tecnologías están teniendo en este proceso es algo fuera de toda cuestión, hasta el punto de que no se puede entender la relación educativa solo como una tríada docentecontenido-alumnado, minusvalorando el medio como exclusivamente un añadido aséptico que facilita el conocimiento. El medio, el instrumento, la tecnología actual no son asépticos, sino que generan cambios en las personas que los utilizan, pudiendo crear comportamientos dependientes y obsesivo-compulsivos como si de máquinas tragamonedas se tratara (Doval, 2017). Por otra parte, defendemos el hecho de que no se puede entender la educación sin la comunicación, sabiendo que no se pueden confundir los dos términos puesto que, en muchas ocasiones, comunicamos sin la intención de educar (Touriñán López, 2019).

Partimos de la visión educativa como una relación que interpela, construyendo valores, procedimientos y contenidos, y que busca el enriquecimiento personal del individuo como ser social situado en un contexto determinado. Vinculamos, por tanto, la educación con el cambio personal, y por extensión con el cambio social. Le damos un carácter de servicio asentado en el seno de la interacción con la propia persona y con las demás, pero sobre todo pensando en los demás sujetos. En este orden de cosas, el papel del personal docente, quien tiene la misión y tarea de interpelar al otro ser, resulta vital; y es que resulta clarificadora la idea de que, cuanto menos peso tiene la educación, más peso tiene la psiquiatría (Cury, 2007). Cuanto menor es el tiempo de la construcción en un proyecto común, más oportunidad hay para una visión sesgada de la vida.

El cambio social requiere de profesionales que entiendan los tiempos y espacios necesarios para promover dicho cambio y que asuman un rol de escrutador social (García Moro et al., 2020). Esta afirmación exige comprender conceptos fundamentales que, por su obviedad, pasan inadvertidos a la luz del entendimiento del que actúa sin pensar. Saber qué profesional defendemos, comprender los tiempos y los espacios en los que nos desenvolvemos, intuir -al menos- lo que supone el hecho de promover, y focalizar nuestros esfuerzos en eso que $\tan$ alegremente todo el mundo llama "cambio", aunque sea lo permanente lo que muchas veces lo caracterice, no son ejercicios banales de una filosofía de la psicología, sino de una psicología y educación que parten de principios filosóficos asentados en una forma de entender y actuar en la vida; no como un mero placer reflexivo, muchas veces objeto legítimo de la filosofía, sino de una necesidad de ser útil para el otro y para el nosotros con el objeto de favorecer el desarrollo pleno de la persona y de la sociedad. 
http://doi.org/10.15359/ree.25-3.39

http://www.una.ac.cr/educare

educare@una.ac.cr

Defendemos una forma transversal de entender el cambio y, por tanto, intercomunicada. Trascendemos las concepciones simplistas que se centran en una variable de la ecuación pretendiendo sobrecalentarla como generadora de cambio. Frente a visiones trascendentalistas del si quiero, puedo anteponemos un enfoque que asume la coexistencia de múltiples realidades, cada una con su peso específico y con la importancia que le damos en un momento concreto. Esta variedad de realidades, motivada por la riqueza de la propia vida y por la obvia complejidad de quienes miramos, obliga a un ejercicio de aprehender para comprender y, si es posible, aprender.

La educación y la psicología, la historia y la epistemología, constituyen pilares fundamentales que coadyuvan a este proceso de vislumbrar lo oscuro y lejano para acercarlo a nuestro entendimiento, pero un entendimiento que se motiva por la utilidad, por usar lo aprendido para propiciar la transformación de las realidades que nos acompañan. Favoreciendo el cambio para la mejora de lo que ontológicamente nos importa o lo que debe de importar.

Defendemos que la vida que merece la pena vivir exige reflexión compartida y con una intencionalidad clara de promoción de los valores que favorecen el buen vivir de las personas. Compartir reflexiones en espacios y tiempos intencionales es una de las características fundamentales de la educación. La intencionalidad es una de las piedras angulares que diferencian una educación con sentido de una información con sentido, aunque aparentemente tenga poco o ningún sentido. Educar al otro en la justicia es trascender la importancia del tú para focalizarla en un contexto de interacción: el nosotros o nosotras.

Esta formación para la vida social justa (Dewey, 1996) requiere de un esfuerzo dirigido por parte de quien educa. Un esfuerzo que se debe de caracterizar, a nuestro parecer, por las siguientes características:

1. Acompañamiento en, desde, por, para y con el otro ser. Obviamente no todo acompañamiento es educativo, sano, oportuno o intencionado. Aquí hablamos de un acompañamiento que interpela desde un sistema de valores; desde la mirada cercana que facilita y habilita en un proyecto conjunto e individual de realización personal en sociedad. Este acompañamiento debe partir del conocimiento del otro como un rostro que cobra sentido educativo, buscando la interpelación desde una posición de conocimiento mediante la comunicación que busca el cambio.

2. Educación en el discernimiento de lo que puede ser importante de lo que solo es urgente; de lo que realmente necesita la sociedad y las personas más que lo que le interesa a la sociedad y a la persona (Doval, 2017). Es tanta la información disponible que materialmente no es posible disponer de tal cantidad y mucho menos asimilarla, si es que es necesario hacerlo. Además, la capacidad crítica resulta fundamental para decidir lo que realmente importa más allá de lo que me interesa. Hablar de dónde estamos conlleva 
inevitablemente hablar de lo que somos. El aletargamiento que produce el bombardeo constante de lo que no se puede abarcar produce una sensación de indefensión para la cual hay que preparar a la persona (Innerarity, 2011; Wolton, 2010). Estamos en la era de los impactos más que en la de los conocimientos; la posverdad acampa a sus anchas fruto de una cultura que parece huir de la realidad o, más aún, llega a confundir la realidad con la virtualidad, y donde la capacidad de atención queda condenada a la incapacidad de abarcar lo que de una forma constante va creciendo (Doval, 2017).

3. Visión multidimensional de la vida, comprendiendo y aceptando que la vida es compleja, que la ambigüedad forma parte de esta y que el proceso de discernimiento para superarla es parte necesaria de la educación con intención de construir un mundo mejor (Morin, 2004). En este sentido, el sujeto escrutador social no debería conformarse con una visión unilateral de la vida; entendiendo que lo que aparece no siempre es lo que debe ser; que la cantidad no tiene que ver con la calidad; y que la virtualidad es una forma de realidad, pero no es la única. Los otros digitales que aparecen en las pantallas no dejan de ser indicadores indirectos de una realidad que trasciende la propia pantalla; en este sentido, es importante reencontrarse con la realidad una vez que se apagan las máquinas (Wolton, 2010).

4. Pragmatismo como modo de defender los valores fundamentales; de los derechos y de los deberes. No como un utilitarismo desbocado conformado con el placer de lo propio y lo ajeno, sino como capacidad y competencia de hacer lo conveniente a la luz de los valores que promueven un desarrollo positivo de la persona como ser situado en un contexto social determinado que le da y al que da sentido (Vázquez y Hervás, 2008).

5. Capacidad de seleccionar y discriminar para combatir el síndrome del pensamiento acelerado (Cury, 2007). La información que existe no es la información que se puede manejar. Facilitar el aprendizaje de las competencias necesarias para la vida plena (Delors, 1996). La solución es algo más que un cúmulo de conocimientos, es la práctica de esos conocimientos; esto supone la defensa de un enfoque basado en competencias: en este caso, las referidas a las que favorecen una vida de calidad, solidaridad, respeto, compasión, protección, inclusión, diversificación, entre otras (UNESCO, 2018). Competencias que alejan a la persona en sociedad de fundamentalismos personales, grupales y virtuales. Competencias que interpelan y desgranan, que abarcan e individualizan, que me hacen mejor y nos hacen mejores, que miran a mí y al otro en un nosotros. Competencias que toleran aparentes contradicciones pero que no admiten lo que atenta contra el bien de la persona y de la sociedad.

6. Importancia de los valores prosociales (UNESCO, 2018) como elementos fundamentales que activan el proyecto-ser humano, el proyecto-sociedad, más allá de visiones sectarias de la propia vida que defienden lo anecdótico de un vosotros y un ellos. En este sentido, 
http://doi.org/10.15359/ree.25-3.39

http://www.una.ac.cr/educare

educare@una.ac.cr

creemos en lo que afirma Barcellona (1996) cuando indica que "el reconocimiento del diferente, del otro, no es ni un lujo ni una obra de caridad, sino la consciencia adquirida de que yo no puedo dar forma a mi identidad sin afirmar la diferencia del otro y custodiarla como una necesidad básica" (p. 114). Nuestra sociedad actual necesita de plataformas comunitarias que vinculen a los unos con los otros en un propósito común: potenciar la buena vida. El individuo, por sí mismo, carece de las estrategias necesarias y suficientes para alcanzar lo máximo a lo que puede llegar. Somos seres sociales y como tales, nos guste o no, necesitamos del nosotros para avanzar; sin embargo, nos atrae la confrontación, el gregarismo, la defensa equivocada de un yo por encima de un tú. Es necesario defender la importancia del individuo en el seno de la comunidad que amortigüe los posibles efectos perniciosos de la vida y que potencie los aspectos saludables y positivos de la misma. Siguiendo a Barcellona (1996),

Si hoy parece necesario criticar la forma histórica bajo la que se ha manifestado el individualismo, la misma en la que sigue manifestándose en el mundo contemporáneo y en nuestra vida cotidiana, no es ya en nombre de una nostalgia comunitaria o de una lamentación por un ethos perdido para siempre, sino sobre la base del fracaso de nuestra capacidad para dar respuestas a los problemas más agudos de nuestro tiempo. (p. 111)

Estamos de acuerdo con Touriñán López (2019) cuando considera necesario asumir una responsabilidad en la relación educativa para la relación educativa. Toda la tradición pedagógica que sitúa a quien educa y al estudiantado en el centro de la ecuación, comoelementos indisociables de un sistema complejo, cobra especial sentido en la actualidad. Cuando la información es tan cercana y accesible, pero el roce resulta tan difícil como incómodo por la distancia espaciotemporal real, que no virtual, resulta fundamental retomar la valía e importancia de la relación cara a cara. En palabras de Wolton (2010), se soñaba con la aldea global, pero se redescubre la torre de Babel, puesto que acceder a la información no es lo mismo que acceder al conocimiento. El mismo Wolton (2010) reflexiona sobre la abundancia de la información en detrimento de la escasez de la comunicación, incluso llegando a afirmar que si cada vez hay más incomunicación se debe a que cada vez hay más información. Es necesario educar para que se aprenda a vivir juntos "desarrollando la comprensión del otro y la percepción de las formas de interdependencia -realizar proyectos comunes y prepararse para tratar los conflictos- respetando los valores de pluralismo, comprensión mutua y paz" (Delors, 1996, p. 109).

La educación interpela parte de la información, pero necesariamente debe llegar al conocimiento a través de la comunicación dialógica, con uno mismo y una misma, con el otro ser o con otros seres. El instrumento no basta per se para crear la función educativa, aunque no es aséptico, sino que incluso modela una forma de relacionarse con el mundo que no siempre es beneficiosa para la persona ni, por tanto, para los demás sujetos. Lo virtual acerca lo que, 
hace poco, era inaccesible por espacio, tiempo y volumen; sin embargo, hace falta educar en determinadas competencias prosociales y propersonales para que la ilusión de lo virtual no se confunda con la mirada que me mira (García Moro, 2015). Más que nunca, la educación intencional que busca favorecer el desarrollo pleno de las personas (Delors, 1996), debe cuidar estos aspectos fruto del avance tecnológico. Obviamente, las bondades que aportan a las personas son incuestionables, como erróneo sería calificarlos como instrumento aséptico.

La educación que se basa en la comunicación debe ubicar y dar sentido, y esto es tan válido para las plataformas presenciales como virtuales de enseñanza y aprendizaje. No cabe duda de que el profesor o profesora que solo se limita a informar está despersonalizando lo que por derecho le corresponde a la educación. Tampoco cabe duda de que una buena preparación de materiales enfocados al e-learning, garantizando espacios y tiempos de tutorización, etc., se constituye, como de hecho ocurre con frecuencia, en espacios educativos de calidad. Pero, al fin y al cabo, de lo que estamos hablando en los dos casos es de responsabilidad, poca en la primera y mucha en la segunda.

La comunicación, antes que nada, es un sistema abierto de interacciones... El predominio de los medios de difusión como centro de la reflexión oscurece las aportaciones de todo lo concerniente al diálogo, al vínculo entre los seres humanos, a la capacidad de estos para comunicarse consigo mismos, con los otros y con el entorno físico y simbólico en el que se desenvuelven. (Rizo García, 2011, p. 13)

\section{Condiciones necesarias para favorecer la responsabilidad educativa}

Esta responsabilidad de la educación, en el sentido más amplio de la palabra, requiere de unas condiciones que, si bien no garantizan el hecho educativo, sí que son necesarias para que se produzca:

1. Persona que asume la responsabilidad de enseñar; entendiéndose esto desde un punto de vista vygotskiano de acompañamiento y oportunidades de aprender en el seno de la sociedad y con la participación intencionada de personas que poseen más competencias y conocimientos para ello (Vygotsky, 2010). La zona de desarrollo potencial es un concepto fundamental de la aportación del eminente psicólogo ruso que remarca la importancia del contexto de aprendizaje y la intención para el aprendizaje; en este sentido, el acompañamiento y orientación de un sujeto experto que prevea lo que el tú pueda alcanzar con su ayuda resulta algo interesante, que podemos relacionar con la filosofía de la alteridad entendida, en este caso, como el valor del otro ser en el proceso de mejora del propio. 
http://doi.org/10.15359/ree.25-3.39

http://www.una.ac.cr/educare

educare@una.ac.cr

2. Persona con intención de aprender más allá de lo que aparece en lo informal de la vida y de su cotidianidad. Obviamente esta intención es menos clara en cortas edades, asumiéndolas normalmente las personas que están a su cuidado. Nos encontramos aquí con una intencionalidad vicaria que permite ir configurando en los niños y niñas de corta edad el marco para ir construyendo su propio futuro en el presente. También, a estas edades la intencionalidad vicaria la asume la escuela y, aunque de intención esté llena, aunque solo sea de carácter informativo y banal muchas veces, la sociedad con sus medios de comunicación de masas, que más propiamente se debería llamar medios de información de masas.

3. Recursos materiales, contenidos, principios, etc., necesarios y que tienen que ver con lo que se enseña o lo que hay que aprender.

4. Tiempo necesario para planificar, favorecer y materializar el proceso de enseñanza/ aprendizaje. Frente a la tentación de lo inmediato, es necesario recordar la importancia de la actitud investigadora de quien se educa y de quien educa. La mera información, si quiere ser dialógica, requiere de un proceso necesario de contrastación y adecuación a lo que se necesita. Hoy en día, con la facilidad de acceso a cualquier tipo de información, con ofertas casi ilimitadas de cursos y con un piélago de temáticas variopintas como creativa es la mente de las personas, parece como si solo con apretar un botón se entrara en un proceso educativo y, por tanto, convivencial. La convivencia, al igual que la educación, necesita tiempo de maduración, puesto que estamos hablando de cambiar esquemas e interpelar al otro individuo atendiendo a sus necesidades y características personales.

5. Asegurarse de que lo que se ha enseñado se ha aprendido. Obviamente aquí la evaluación y la oportunidad de que la persona pueda poner en práctica lo aprendido son los elementos definitorios que retroalimentan el proceso educativo; y no estamos hablando de utilidad, sino de la capacidad y posibilidad de usar lo aprendido. Esta capacidad y posibilidad no siempre se dan conjuntamente; la dificultad en el acceso al mercado laboral tiene parte de culpa de esto. La capacidad no siempre va acompañada de la posibilidad, y cuántas posibilidades se derrochan por inadecuadas capacidades. En este punto es importante el concepto de competencia, el cual se entiende como "la capacidad de movilizar adecuadamente el conjunto de conocimientos, capacidades, habilidades y actitudes necesarias para realizar actividades diversas con un cierto nivel de calidad y eficacia". (Bisquerra Alzina y Pérez Escoda, 2007, p. 63)

\section{Las plataformas virtuales de información}

Esta complejidad de la educación como elemento definitorio de un proceso enriquecido de intencionalidad basada en un conocimiento cara a cara del otro no queda tan claramente reflejada en las plataformas virtuales de formación. Sí es cierto que se prevé y considera que el otro ser al que se dirige la información diseñada en las comunidades virtuales de aprendizaje es 
merecedor de una historia de vida concreta, pero, al fin y al cabo, presupuesta. Pero ¿hasta qué punto se puede abarcar en una relación dialógica real el devenir informativo de lo virtual? Está claro que se producen interacciones y trasvase de conocimientos; está claro que la disponibilidad de información, de ritmos, tiempos y recursos son mucho más ilimitados; pero, ¿dónde queda lo carnal, el roce del conocimiento que se trasforma en educación? (García Moro, 2015) ¿Dónde queda el otro individuo (alumno y alumna) que al fin y al cabo es un yo que me mira? Las nuevas técnicas de la formación están lejos de ser educación en el sentido que la filosofía de la alteridad entiende ese cara a cara en exclusividad (Lévinas, 1997).

Zilka y Zeichner (2019) apuntan que, en un entorno de aprendizaje virtual o mixto, las personas estudiantes pueden percibir la situación como un reto o una amenaza. En su investigación, indican que la separación física entre docente y alumnado puede conducir a una distancia transaccional, que a su vez puede causar un sentido de amenaza y crear enojo, lagunas en la comprensión o conceptos erróneos este último sobre sí mismo y sobre el proceso de aprendizaje. La persona estudiante puede entender la situación como un desafío o una amenaza. Estos estudios encontraron que la comunicación interpersonal diferencial, la retroalimentación y los foros pueden llevar a una disminución en los sentimientos de amenaza y a un aumento en el sentido de desafío. Algunos individuos solo necesitan una interacción intelectual; otros necesitan tanto una interacción intelectual como emocional.

Esta variabilidad de una persona, por obvia, se camufla y olvida. Lo que puede funcionar para la mayoría no funciona para otros individuos. Lo virtual sin un acompañamiento cercano que mire al sujeto que mira puede servir, pero no a todo el mundo. Ese distanciamiento de lo cercano quizá sea asumible cuando los pilares que permiten a la persona desenvolverse de una forma autónoma y responsable por el mundo estén mínimamente consolidados; pero mientras tanto, es necesaria la cercanía y el trato directo que permita el trasvase de historias de vida. Estamos de acuerdo con Touriñán López (2019) y Wolton (2010) cuando reflexionan sobre el carácter convivencial de la comunicación y de la educación. Si comunicar es convivir, puesto que busca la interpelación del otro ser, defendemos que la educación que enriquece es aquella que parte de interacciones convivenciales de conocimientos. No obstante, es necesario reiterar que se puede educar desde plataformas virtuales, e igualmente se puede tratar al otro como a un extraño, sin historia de vida, en contextos educativos presenciales.

\section{El pensamiento crítico como competencia de responsabilidad educativa}

Olivares Olivares y López Cabrera (2017) insisten en la importancia fundamental de que la persona estudiante vaya aprendiendo y desarrollando habilidades, destrezas y competencias que le permitan enfocar adecuadamente la hiperinformación de la sociedad actual; competencias como la capacidad de establecer juicios y argumentaciones más allá de la mera opinión. Y es que estamos de acuerdo con Paul y Elder (2003, p. 2) cuando afirman que "Aquel que piensa críticamente tiene un propósito claro y una pregunta definida. Cuestiona la información, las 
http://doi.org/10.15359/ree.25-3.39

http://www.una.ac.cr/educare

educare@una.ac.cr

conclusiones y los puntos de vista. Se empeña en ser claro, exacto, preciso y relevante. Busca profundizar con lógica e imparcialidad".

Nuestra calidad de pensamiento es primordial para que nuestra vida sea una vida de calidad, tanto desde el punto de vista personal como social; no obstante, lo cierto es que mucho del pensamiento que ejercemos se caracteriza por ser errático como consecuencia de los prejuicios, los sesgos, las falacias que empleamos en nuestras argumentaciones, la desinformación, la apatía o el peso desmesurado de una información que nos narcotiza con su velocidad y magnitud, independientemente de su utilidad, idoneidad y oportunidad.

El pensamiento crítico es tan importante hoy en día que, tal y como apunta Franco et al. (2014), constituye un recurso cognitivo fundamental que se relaciona con el rendimiento académico y el éxito en la vida cotidiana.

Pero ¿qué es el pensamiento crítico? Definirlo no es una tarea sencilla, puesto que se puede entender de diversas formas y desde diferentes perspectivas. Tal es así que se ha entendido como un proceso de pensamiento lógico y científico, o como una posición de desaprobación contestataria hacia algo o alguien, o como un procedimiento para reflexionar o filosofar. A la hora de aproximarse al concepto de pensamiento crítico, se ha hecho y hace desde diferentes disciplinas, buscando cada una de ellas su desarrollo y su aplicación (Altuve, 2010; González Valencia y Morillo Puente, 2018; Vélez Gutiérrez, 2013). La filosofía, la psicología, la sociología o la pedagogía ofrecen sus propias definiciones, aunque a grandes rasgos se considera como un proceso cognitivo que implica evaluación y reflexión o como una habilidad que favorece la construcción de un conocimiento nuevo y la solución de problemas presentes en la vida cotidiana. En todo caso, tal y como apunta Valenzuela y Nieto (2008), no hay una definición de pensamiento crítico que sea comúnmente aceptada debido a que su naturaleza es multicompleja.

Facione, uno de los autores que más ha investigado sobre pensamiento crítico, lo define como la capacidad de desarrollar un juicio que se caracteriza por su autorregulación y que tiene un propósito concreto y delimitado, cuyo resultado se explica a partir de las evidencias, los conceptos, los métodos, criterios y contextos que previamente se consideraron para establecer dicho juicio (Facione, 1990). El mismo autor indica que el pensamiento crítico se define por ser un pensamiento elaborado que depende de la propia persona que busca un objetivo. No estamos hablando, por tanto, de un pensamiento latente, sino focalizado en entender cuestiones desgranando la verdad de lo que aparece. Olivares Olivares y López Cabrera (2017), por su parte, lo definen como la capacidad de desarrollar un juicio basado en datos objetivos y subjetivos que han sido interpretados y analizados con anterioridad, facilitando a la persona inferir las consecuencias de sus propias decisiones.

Paul y Elder (2003) consideran que la persona que se caracteriza por pensar críticamente tiene la capacidad real de cuestionarse acerca de los problemas fundamentales de una manera 
http://doi.org/10.15359/ree.25-3.39

abierta, reconociendo y valorando las implicaciones; teniendo la habilidad de recopilar información significativa para dicho fin, así como evaluar su pertinencia e idoneidad; llegando a conclusiones convenientemente razonadas, y teniendo la destreza de comunicar, ante los problemas, alternativas.

Este conjunto de habilidades no se adquiere sin esfuerzo y dedicación; aún más, resulta fundamental, siguiendo las aportaciones vygotskianas, que coparticipen otros sujetos más expertos.

Si repasamos las habilidades propuestas anteriormente por Paul y Elder (2003), no cabe duda de que la cuestión de lo que es o no esencial está supeditada a un conjunto más o menos extenso de variables; obviamente, desde un punto de vista general y referido a nuestro ámbito educativo, lo esencial es lo que apunta al bien de la persona; siendo un elemento valedor fundamental la promoción de los derechos -y de los deberes- de la misma. Ya esto, en sí mismo, resulta problemático teniendo en cuenta las características de nuestra sociedad actual y del relativismo ético y partidista en el que nos encontramos. Debatir sobre qué es lo esencial para la persona y la sociedad no es para nada un tema baladí, sino fundamental a la hora de entender que somos un proyecto inacabado que necesita constantes mejoras. La educación es un derecho y la información emitida tiene el deber de sumar en esta dirección. En cuestión de derechos, por ejemplo, el sujeto escrutador social es testigo de la paradoja de tener o avanzar en la adquisición de más derechos sociales y personales; sin embargo, este proceso no va solo, sino que parece crecer al mismo tiempo que los mecanismos que crean nuevas necesidades y alienan a la persona en sociedad (García Moro, 2015). Tal y como apunta García Inda (2008), este choque de fuerzas genera una sensación de vaciamiento influido por cuatro circunstancias que influyen en nuestro posicionamiento hacia lo que significan los derechos humanos:

- El hartazgo de lo que significa debido a etiquetar gran parte del discurso social con lo que es el derecho del hombre, de la mujer, del niño, de la persona con discapacidad, etc. Está tan en boca de todo el mundo que parece que todo el mundo sabe de lo que habla, confundiéndose 'opinión' con 'argumentación basada en el conocimiento'. Los temas fundamentales que más íntimamente interpelan a la persona son los temas, quizá, más complicados de educar por lo que le suponen a la persona en cuanto realidad discursiva materializada en historias de vidas entrelazadas.

- La hiperabstracción de lo que significa, dificultando su composición y credibilidad, porque cuando llega el inevitable momento de particularizar, de poner rostro al otro concreto (Lévinas, 1997), nos damos cuenta de quetiene ideología, sexo, carácter, historia de vida, no coincidiendo muchas veces con nuestro modelo abstracto de lo humano. Con mucha frecuencia, la información que no-comunica parte de planteamientos abstractos que aleja, en nuestro caso, al educando de la realidad del otro como persona social que se desenvuelve en un contexto sociocomunitario determinado, con una historia de vida particular, con unas necesidades y características determinadas.

- Los derechos de una minoría poderosa imperan sobre los derechos de una mayoría subyugada. Parece que esta ecuación ha sido la predominante en la historia de la 
humanidad, incluso a pesar de los esfuerzos por democratizar lo que por derecho le corresponde a todo hombre, mujer, niño o niña. El poder de lo que se transmite está en manos de unos pocos individuos procedentes de aún más pocos países que monopolizan la información, aunque no el conocimiento. En este sentido, la visión del ente escrutador social será la de velar para que la comunicación que quiere educar no sea toda la información que quiere llegar, y que esa comunicación sea coherente con los principios y valores inclusivos.

- Tecnificación de los derechos desvinculando su responsabilidad de todas las personas para ubicarlas en unas pocas: los que saben, los expertos y expertas, los ejecutores. En este punto, resulta interesante observar cómo la información que nos viene de los medios virtuales, debido a su extrema rapidez, a su facilidad para acceder -aunque no sepamos siempre a lo que queremos acceder o a lo que accedemos- se le concede un cierto boato de autoridad experta, cuando en realidad no siempre es así. En esta línea, no siempre sabemos las credenciales de quienes informan a través de internet, ni mucho menos las intenciones; y ya si nos centramos en nuestra reflexión educativa, ni hablemos de la intención establecida en función de las necesidades del que recibe la información. Obviamente no todos los portales pecan de esto, pero... nos exigen tomar partido como investigadores e investigadoras que saben escrutar lo que hay, no buscando la imposibilidad de aparecer expertos de todo, sino de saber lo que suma y lo que resta, eligiendo de una forma responsable en función de principios y valores sólidos.

\section{La reivindicación de una ética del pensamiento consciente en una sociedad de cambio}

Esta realidad social y personal, puesto que son elementos indisociables de la misma ecuación, requiere de un replanteamiento de los elementos más íntimamente humanos, siendo uno de ellos el pensamiento, desde la luz de otro elemento constitutivo que es la ética. Y todo ello en un ámbito tan importante como es el educativo, independientemente de los útiles que se utilicen. No podemos hablar de educación en general sin referirnos a la ética, puesto que "la acción educativa es, en suma, una acción ética" (Campillo Díaz y Sáez Carreras, 2012, p. 33).

En una sociedad hipermoderna, caracterizada por la incertidumbre y la sensación de vacío (Lipovetsky, 2006), por la necesidad de un consumo de la información sin llegar muchas veces al conocimiento (Cury, 2007) y por el imperativo que muchas veces siente la persona de adaptarse a una sociedad cambiante, globalizada pero que mira a lo concreto sin unos pilares claros (Bauman, 2007), no basta con dominar competencias profesionales ejecutoras de capacidades aprendidas, sino que se necesita una sólida preparación ética y una adecuada destreza crítica para vislumbrar lo adecuado y separarlo de lo pernicioso.

En una sociedad de cambio, quienes educan -y la persona en general- tienen la responsabilidad ética de reflexionar acerca de la realidad que no es pero que debe ser (Petrus 
http://doi.org/10.15359/ree.25-3.39

Rotget, 1998), evitando los prejuicios y teniendo en cuenta lo que necesita el otro ser (Doval, 2017); teniendo cuidado de no marcar la acción educativa con nuestros deseos por encima del bien de la persona (Sen, 2010), y teniendo en cuenta la importancia de seguir construyendo un nosotros en una sociedad que acompaña y que no excluye; con una actitud de servicio hacia lo que realmente importa: el conocimiento que autorrealiza.

Cualquiera que de alguna manera sea parte de [la] sociedad tiene que sentirse responsable y en deuda con esa sociedad porque no puede vivir aislado, depende de esa sociedad; el que vende depende de esa sociedad, el que comunica depende de [esa] sociedad..., no pondría yo a los comunicadores para el cambio social "por encima" de otros miembros de la sociedad. (Gumucio Dagron en Pérez et al., 2009, p. 287)

A la hora de implicarse, de interactuar, de conocer y contar historias de vida, porque sería perjudicial para el desarrollo pleno del uno y del otro vivir encarcelado en su propio mundo (Cury, 2007), es necesario replantearse una serie de cuestiones que afectan a la ética del ente escrutador social y cuya reflexión requiere inevitablemente de la coparticipación de la otra persona. Son cuestiones que no apuntan exclusivamente a la reflexión de un campo profesional, sino que dan en la diana de lo que toda persona necesita en la sociedad hiperconectada de hoy: educación que libere desde la responsabilidad; teniendo la capacidad de decidir lo que es esencial por encima de lo que no lo es, y más aun teniendo en cuenta la capacidad de engaño de lo que muchas veces se nos presenta como real aunque en esencia sea una realidad virtual o incluso una presencialidad sin consistencia ni finalidad que apunten al bien de la persona.

- El punto de partida y de llegada de quien educa y escruta empieza y termina con la persona en sociedad. Es importante tener en cuenta este principio fundamental que supera cualquier consideración que relativice lo permanente. Entender que la información parte para llegar a personas que le quieran dar sentido es ubicar el mensaje en un contexto dialógico y, por tanto, de comunicación educativa.

- Decidir lo que quiero hacer con la información que emito o recibo es fundamental, puesto que el sentido e importancia de las cosas no siempre van acompasados con el tiempo, el medio o el contexto. Por otra parte, lo que se necesita requiere de una mínima reflexión que muchas veces la infobesidad, tal como dice Wolton (2010), dificulta. En este sentido, es importante comprender que, si el exceso de información puede confundir o bloquear, la persona con las herramientas adecuadas de investigación, conocimiento, pensamiento crítico y educación, en definitiva, puede y debe superarlo. Educar, comunicar, es una cuestión que tiene que ver con la convivencia y el vínculo social, no tanto con el contenido; somos en esencia sociales, no contenedores de información.

- ¿Cuál es mi posición? ¿De dónde parto? ¿Qué defiendo y qué denuncio?

- ¿Qué puedo hacer? 
http://doi.org/10.15359/ree.25-3.39

http://www.una.ac.cr/educare

educare@una.ac.cr

- ¿Cómo me comunico con el otro ser para ser un nosotros/nosotras en el contexto?

- ¿Quién es el otro ser? ¿Cuáles son sus potencialidades? ¿Cuáles sus necesidades?

- ¿Cómo es el contexto en el que estoy, puedo y quiero estar?

- ¿Cómo es el contexto en el que el otro ser está, puede y quiere estar?

- ¿Cómo es el contexto en el que estamos, podemos y queremos estar?

\section{Conclusiones}

- Educar es comprometerse para que se comprometan en una sociedad en la que la consciencia de lo que hay y de lo que pasa debe ser superada por el conocimiento reflexivo de lo que hay y pasa; no solo como mecanismo de focalización y definición de textos en diferentes contextos, sino como procedimiento que busca interpelar para la mejora desde el buen hacer y de la potencialidad del buen ser. Hoy, más que nunca, la persona debe tener la habilidad suficiente de entrever al otro ser entre la información indiscriminada de otros individuos. La necesidad del encuentro cara a cara resulta esencial para recordarnos la importancia de la palabra como motor de cambio cuando va acompañada de historias de vida concretas. La virtualidad sin cumplir con estos principios fundamentales puede ser tan perniciosa como la educación presencial que elimina lo más intrínsecamente genuino que tiene el otro ser: el acto y la potencia de ser buena persona en sociedad.

\section{Declaración de Material complementario}

Este artículo tiene disponible, como material complementario:

-La versión preprint del artículo en https://doi.org/10.5281/zenodo.4067047

\section{Referencias}

Altuve, J. G. (2010). El pensamiento crítico y su inserción en la educación superior. Actualidad Contable Faces, 13(20), 5-18. https://doi.org/10.5944/educxx1.1.10.297

Barcellona, P. (1996). Postmodernidad y comunidad. El regreso de la vinculación social. Trotta.

Bauman, Z. (2007). Los retos de la educación en la modernidad líquida. Gedisa.

Bisquerra Alzina, R. y Pérez Escoda, N. (2007). Las competencias emocionales. Educación XXI, 10, 61-82. http://www.ub.edu/grop/wp-content/uploads/2014/03/Las-competenciasemocionales.pdf

Campillo Díaz, M.y SáezCarreras,J.(2012). Por unaética situacional en Educación Social. Pedagogía Social. Revista Interuniversitaria, (19), 13-36. https://doi.org/10.7179/PSRI 2012.19.02 
http://doi.org/10.15359/ree.25-3.39

Cury, A. (2007). Padres brillantes, maestros fascinantes. No hay jóvenes difíciles, sino una educación inadecuada. Zenith/Planeta.

Delors, J. (Editor). (1996). La educación encierra un tesoro. Santillana.

Dewey, J. (1996). Liberalismo y acción social y otros ensayos. Edicions Alfons el Magnànim.

Doval, M. (2017). Comunicación efímera. De la cultura de la huella a la cultura del impacto. Kindle ediciones. $\quad$ https://www.amazon.es/Comunicaci\%C3\%B3n-ef\%C3\%ADmera-culturahuella-impacto/dp/1976705495

Facione, P. A. (1990). Critical thinking: A statement of expert consensus for purposes of educational assessment and instruction. California Academic Press. https://www.researchgate.net/ publication/242279575_Critical_Thinking_A_Statement_of_Expert_Consensus_for Purposes of Educational Assessment and Instruction

Franco, A. R., Almeida, L. S. y Saiz, C. (2014). Pensamiento crítico: Reflexión sobre su lugar en la Enseñanza Superior. Educatio Siglo XXI, 32(2), 81-96. https://doi.org/10.6018/j/202171

García Inda, A. (2008). Identidades y derechos colectivos. En R. S. Beltrán y D. S. M. Segura (coords.), De identidades. Reconocimiento y diferencia en la modernidad líquida (pp. 75-191). Universidad de la Rioja-Tirant lo Blanch.

García Moro, F. J. (2015). Competencias psicológicas del profesional de la educación social. Universidad de Huelva.

García Moro, F. J., Gadea Aiello, W. F. y Palomo García, M. (2020). Educación para el cambio. En G. García, J. A. Nicoletti y W. F. Gadea Aiello (coords.), Educación y participación para una sociedad inclusiva (pp. 12-26). Ciencia y Técnica Administrativa. http://www.cyta.com.ar/ biblioteca/bddoc/bdlibros/Educa y Participa.pdf

González Valencia, G. y Morillo Puente, S. (2018). Representaciones sobre el desarrollo del pensamiento crítico en maestros en formación. Revista Brasileira de Educação, 23, 1-25. http://dx.doi.org/10.1590/S1413-24782018230086

Innerarity, D. (2011). La democracia del conocimiento. Por una sociedad inteligente. Paidós.

Lévinas, E. (1997). Totalidad e infinito. Sígueme.

Lipovetsky, G. (2006). Los tiempos hipermodernos. Anagrama.

Morin, E. (2004). Introducción al pensamiento complejo. Gedisa.

Olivares Olivares, S. L. y López Cabrera, M.V. (2017). Validación de un instrumento para evaluar la autopercepción del pensamiento crítico en estudiantes de Medicina. REDIE. Revista Electrónica de Investigación Educativa, 19(2), 67-77. https://doi.org/10.24320/ redie.2017.19.2.848 
http://doi.org/10.15359/ree.25-3.39

http://www.una.ac.cr/educare

educare@una.ac.cr

Paul, R. y Elder, L. (2003). La mini-guía para el pensamiento crítico. Conceptos y herramientas. Fundación para el Pensamiento Crítico. https://www.criticalthinking.org/resources/PDF/ SP-ConceptsandTools.pdf

Pérez, G. J.., Cataño Otárola, M. M. y Franco Chávez, F. P. (2009). Comunicar para el cambio social: Una comunicación ética y política. Entrevista con Alfonso Gumucio Dagron. Signo y Pensamiento, 28(55), 278-290. http://148.215.2.11/articulo.oa?id=86020246018

Petrus Rotger, A. (1998). Concepto de educación social. En A. Petrus (Coord.), Pedagogía social (pp. 9-39). Ariel.

Rizo García, M. (2011). Pensamiento sistémico y comunicación. Razón y Palabra, (75), 1-13. http:// www.razonypalabra.org.mx/N/N75/monotematico 75/29 Rizo M75.pdf

Sen, A. (2010). La idea de la justicia. Taurus.

Touriñán López, J. M. (2019). La relación educativa es un concepto con significado propio que requiere concordancia entre valores y sentimientos en cada interacción. Sophia, colección de Filosofía de la Educación, (26), 223-279. https://doi.org/10.17163/soph.n26.2019.07

UNESCO. (2018). Avances en la educación para el desarrollo sostenible y la educación para la ciudadanía mundial. Autor. https://unesdoc.unesco.org/ark:/48223/pf0000266176 spa?p osInSet=276\&queryld=039a4cfb-059e-46a0-b5d5-a8afc31b2bee

Valenzuela, J. y Nieto, A. M. (2008). Motivación y pensamiento crítico: Aportes para el estudio de esta relación. Revista Electrónica de Motivación y Emoción, 11(28), 1-8. http://reme.uji.es/ articulos/numero28/article3/article3.pdf

Vázquez, C. y Hervás, G. (2008). Salud positiva: Del síntoma al bienestar . En C. Vázquez y G. Hervás (Eds.), Psicología positiva aplicada (pp. 17-40). Desclée de Brouwer.

Vélez Gutiérrez, C. F. (2013). Una reflexión interdisciplinar sobre el pensamiento crítico. Latinoamericana de Estudios Educativos, 9(2), 11-39. http://vip.ucaldas.edu.co/ latinoamericana/downloads/Latinoamericana9(2) 2.pdf

Vygotsky, L. (2010). Pensamiento y lenguaje. Paidós.

Wolton, D. (2010). Informar no es comunicar. Gedisa.

Zilka, G. C. y Zeichner, O. (2019). Factors necessary for engaging preservice teachers studying in virtual and blended courses. International Journal of Mobile and Blended Learning (IJMBL), 11(1), 42-57. https://doi.org/10.4018/IJMBL.2019010104 